Europe's Journal of Psychology 4/2009, pp. 52-70

www.ejop.org

\title{
Factorial Structure and Psychometric Properties of the Maslach Burnout Inventory (MBI) in Greek Midwives
}

\author{
Michael Galanakis \\ PhD, MSc, Organizational Psychologist, \\ Panteion University of Political and Social Sciences
}

\section{Martha Moraitou}

PhD, Midwife, Adjunct Lecturer,

Department of Midwifery, Alexandreio Technological Educational Institute of Thessaloniki

\section{Filia J. Garivaldis,}

MOrg, Organizational Psychologist, Doctoral Psychology Student,

Monash University, Australia

\section{Anastasios Stalikas}

PhD, Psychologist, Psychology Professor,

Panteion University of Political and Social Sciences

\begin{abstract}
Burnout is a variable that continues to sustain international research interest. The most widely adopted tool measuring the burnout syndrome is the Maslach Burnout Inventory $(\mathrm{MBI})$. The present study attempted to examine the psychometric properties and factorial structure of the $\mathrm{MBI}$ amongst a sample of 536 professional health specialists in Greece. The results indicated satisfactory reliability through internal consistency for all three dimensions. However, a factor analysis did not produce conclusive evidence of a tripartite construct, but rather the predominance of a single primary factor (emotional exhaustion), and a secondary factor (depersonalization). The results confirm previous findings advocating the uni-factorial or bi-factorial nature of the construct.
\end{abstract}

Keywords - Burnout, Maslach, MBI, factorial structure, psychometric properties, midwives. 
Scientific interest in the study of the burnout syndrome has evolved in recent years (Anagnostopoulos \& Papadatou, 1992), and has become a growing phenomenon in the workplace context (Ahola \& Hakanen, 2007; Borritz et al., 2005; Gonzalez-Rom, Schaufeli, Bakker, \& Lloret, 2002; Laschinger \& Leiter, 2006; Leiter, 2005; Maslach, 1993; Pines \& Keinan, 2005). The first reference ever made to the term burnout was in 1974, when Freudenberger observed a series of symptoms of exhaustion in the context of the workplace. Since then, Pines and Maslach (1978) describe burnout as a syndrome of somatic and psychological exhaustion with multiple classifications. Burnout manifests as a subjective feeling of dysphoria, impacting on physical and emotional aspects of one's wellbeing, and leading to a reduction of behavioural activity and motivation, and the debilitation of one's efforts to perform (Maslach \& Jackson, 1982). Moreover, burnout results from the inability to stabilize internal and/or external needs, and as a consequence inhibits the allocation of energy resources effectively (Maslach \& Leiter, 2005). Burnout may also result from a situation where minimal rewards are bestowed for a goal in which a large investment was made (Rupert \& Morgan, 2005; Schaufeli \& Baker, 2004).

In two empirical studies, Maslach and Pines $(1977,1978)$ documented the symptom of somatic and psychological exhaustion, accompanied by a lack of sleep and headaches, amongst a sample of nurses. These symptoms were found to precipitate cynicism between colleagues, negativity towards patients, withdrawal from social contact within the workplace environment, and performance at bare minimum standards. Finally, nurses who were found to exhibit this sequence of symptoms reported disappointment and dissatisfaction across many domains, including disappointment with themselves. Research on burnout began to unfold through clinical studies, allowing the construct to become recognized, at least in the health sector (Anagnostopoulos \& Papadatou, 1992; Ahola \& Hakanen, 2007; Montgomery, Panagopoulou, \& Benos, 2006; Vahey et al., 2004).

Moreover, burnout has been associated with negative workplace behaviours such as increases in sick leave, premature retirement (resignation), alcohol abuse, increases in smoking and coffee consumption, familial, social, and economic problems, workplace accidents, interruptions in the provision of quality of service, low morale, and frequent job changes (Bakker et al., 2000; Chatzimihaloglou, Moraitou \& Emmanouil, 2005; Demerouti et al., 2001; lerodiakonou \& lakovides, 1997; Leiter, 2005; Leiter et al., 2007). Due to its gradual onset (Kiuru et al., 2008; Leiter \& Maslach, 2005; Montgomery, Panagopoulou \& Benos, 2006;), burnout results from the accumulation of stress that exhausts individuals to the point where their energy resources are insufficient for their attempts to survive the pressure of a situation (Galanakis, Stalikas, Kallia, Karagianni \& Karela, 2009; lerodiakonou \& lakovides, 
1997; Rupert \& Kent, 2007, Papadatou \& Anagnostopoulos, 1999; Schaufeli et al., 2002; Shirom, 2002; Truchot \& Deregard, 2001). As such, burnout has been observed primarily within occupations that involve communication with others, and the selling of services (Ahola \& Hakanen, 2007; Montgomery, Panagopoulou, \& Benos, 2006; Papathanasiou, 2007; Rupert \& Kent, 2007; Vahey et al., 2004).

The plenitude of research on the phenomenon of burnout renders the need for its measurement and diagnosis as imperative, especially if one considers the adverse outcomes that it generates. Consequently, burnout has been operationalized internationally based on Maslach's theoretical framework (Maslach \& Jackson, 1981; 1986). This framework recognises a single syndrome defined by three components; (1) emotional exhaustion, which manifests when individuals are unable to psychologically give of themselves to the degree expected of them, and are therefore behaviourally inapt at investing in effort towards performing, (2) depersonalization, which involves withdrawal, and the distancing of oneself from colleagues and clients resorting to impersonal relationships and remote contact, (3) the feeling of reduced personal accomplishment, which results from negative selfevaluations, and involves a decrease of productivity and the resignation of any effort to perform. This factor is also related to feelings of unhappiness and overall job dissatisfaction (Maslach, Jackson, \& Leiter, 1996).

In order to assess burnout, Maslach and Jackson (1981) developed the Maslach Burnout Inventory (MBI), which consists of 22 items that load onto the three factor structure mentioned above: emotional exhaustion (EE; nine items), depersonalization (DP; five items), and personal accomplishment (PA; eight items). The results of this inventory consist of three separate scores, one for each factor. A combination of high scores on EE and DP, and a low score on PA, correspond to a high level of burnout. The $\mathrm{MBI}$ is the most widely used instrument internationally, as it has been translated into several languages. The most recent version of the instrument is the MBI-Educator's Survey (MBI-ES; Maslach, Jackson, \& Leiter, 1996), which has received verification for its psychometric properties and factor structure across a large sample of US teaching professionals.

A recent study by Kokkinos (2006) attempted to assess burnout across a sample of 771 educators in Cyprus, utilizing a Greek translation of the MBI-ES (MBI-ES; Maslach, Jackson, \& Leiter, 1996). The study conducted exploratory and confirmatory factor analysis, and found support for the three factor structure of burnout. In addition, satisfactory psychometric properties for the Greek translation of the scale were obtained, indicating that the MBI-ES is a reliable and valid measure of burnout across the Greek teaching profession. 
Despite the wide recognition and application of Maslach's framework, burnout's dimensionality has been questioned on several occasions, proposed by some as having a four factor structure (Iwanicki \& Schwab, 1981), and by others as comprising of five factors (Densten, 2001). Densten (2001) asserts that burnout is comprised of two EE factors, psychological and somatic strain, two PA factors, self and others' views to achieve, and a single DP factor. The differences observed regarding the dimensional structure of burnout may be attributed to the various occupations that are assessed. For instance, Maslach and Jackson's (1981; 1986) three factor structure is supported by teachers' samples (Kokkinos, 2006), whereas Densten's (2001) results were observed from a sample of Australian law enforcement managers. Similarly, an examination of the framework across health professionals may yield different results again.

Research in the nursing industry, for instance, has drawn attention to the pronounced pressure and demanding environment of intensive care divisions within hospitals. This context is said to contribute to the psychological burden experienced by its employees (Ahola \& Hakanen, 2007; Montgomery, Panagopoulou \& Benos, 2006; Ouzouni, 1999; Vahey et al., 2004). In Greece, researchers have focussed on burnout amongst nurses (Adali \& Lemonidou, 2001; Anagnostopoulos \& Papadatou, 1992;. Melissa, Avramika, \& Laloumi, 2003; Mpellali, 1998; Papathanasiou, 2007; Ziogou, et al, 1998), but are yet to draw their attention to the specific category of obstetrics. Midwives may be equally or more susceptible to burnout due to their responsibilities in both nursing and obstetrics, as well as having to cope with the additional demands of crisis management and other emergency situations within the delivery room and the intensive care units (Chatzimihaloglou, Moraitou, \& Stalikas, 2003). Studies in England (Sandall, 1998), Denmark (Engelbrecht, 2006), and the Netherlands (Bakker, Groenewegen, Jabaaij, Meijer, Sixma \& de Veer, 1996) have supported the claim that midwives experience severe degrees of emotional exhaustion that is related to their work.

As such, the aim of the current research is to examine the factorial structure and psychometric properties of the Greek version of the Maslach Burnout Inventory in relation to the results of the USA and Cyprus analogous studies. 
Method

Participants

The sample used in the present study consists of 536 Greek midwives/obstetricians. Of these, $97.6 \%$ are females, and $2.4 \%$ are males. Fifty five and a half percent (55.5\%) of participants live and work in the major cities, namely Athens and Thessaloniki, whereas the remainder $44.5 \%$ are from rural areas of Greece. The mean age of participants is 37.85 years $(S D=8.91)$, and the number of years of professional midwifery experience is $13(S D=9)$.

Tools

Data collection involved the use of the latest version of the Maslach Burnout Inventory (MBI) (Maslach et al., 1996). The Greek version of this scale was used as derived from a direct translation of the original (Kokkinos, 2006). The MBI consists of 22 items distributed across the 3 dimensions of Maslach's $(1978,1981,1986)$ theoretical framework discussed above; (a) emotional exhaustion (EE; nine items), (b) depersonalization (DP; five items), and (c) the feeling of personal accomplishment (eight items). The frequency of burnout symptoms is rated on a seven point likert scale ranging from 'never' to 'always'. In application, and whilst measuring a single construct, the $\mathrm{MBI}$ produces three separate scores, one for each of the three subscales. For the purposes of diagnosis, burnout is experienced when at least 2 of the 3 dimensions yield high scores. This scale has been primarily used in the assessment of burnout amongst various professions (Kokkinos, 2000, 2006, Schaufeli \& Janczur, 1994), across many countries, and has yielded satisfactory convergent validity.

Procedure

The $\mathrm{MBI}$ was administered to midwives/obstetricians during a professional conference in 2006. This conference attracted health professionals from all geographical locations of Greece. Each participant received the MBI during the conference, and voluntarily completed it in a group setting. 
Results

Psychometric Properties of the Scale

The raw data was compiled, and analysed using the statistical package SPSS V.14. An analysis of the scale's psychometric properties, including reliability (Cronbachs a), and factor analysis were conducted. Furthermore, the results were examined as a function of gender, age, and professional midwifery experience. The results are presented in light of the psychometric properties of Maslach et al.'s (1996) original US sample, and the recent study conducted by Kokkinos (2006) using a sample of Cypriot teachers.

Table 1. displays the raw data (means and standard deviations) of the results of each of the three subscales of the MBI, against the results of the original US teacher sample (Maslach et al., 1996), and the Cypriot sample of teaching professionals (Kokkinos, 2006).

Table 1. Means and standard deviation for the Greek, US and Cypriot samples, across each of the three dimensions of the MBI

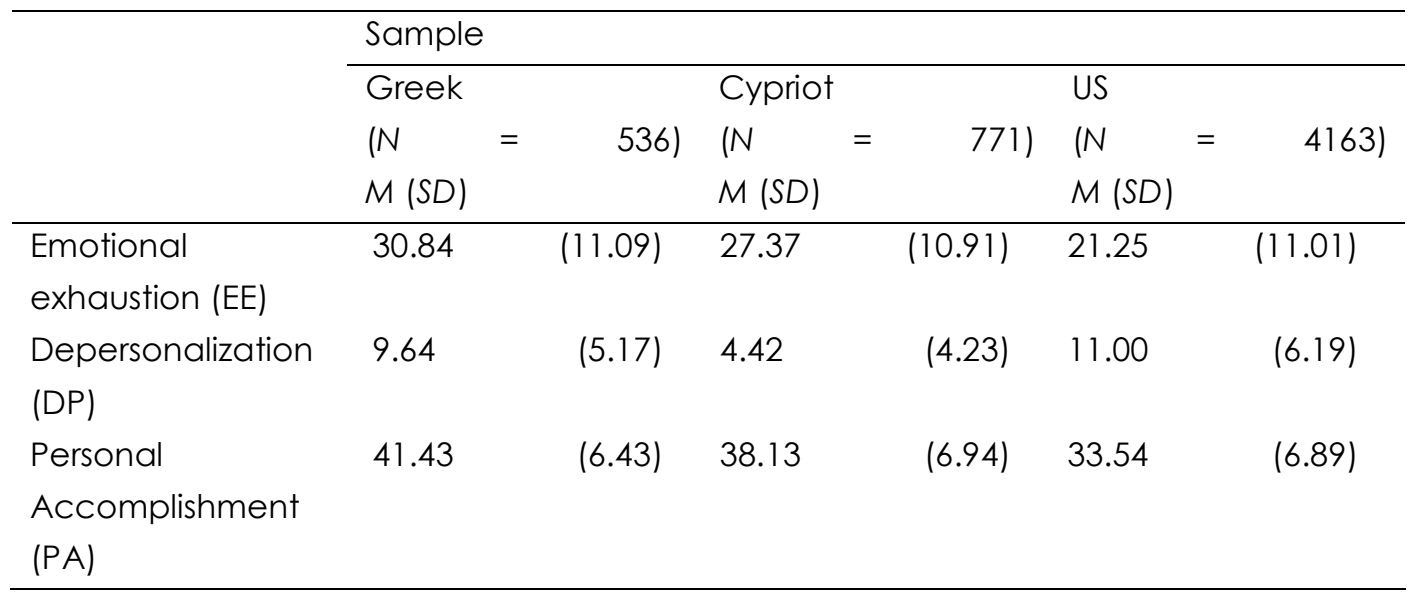

As can be seen from the table above, the Greek sample of the current study has received higher scores of EE. In other words, the Greeks experience more stress and overexertion, although they feel rewarded and satisfied with the outcomes of their efforts. With regard to the depersonalization score, however, the Greek sample scored a little less than the US sample, but almost double the Cypriot sample.

Table 2. below displays the intercorrelations for the $\mathrm{MBI}$ subscales for each of the three samples, Greek, Cypriot and the US. 
Table 2. Internal consistency coefficients across all three samples, and Pearson's $r$ correlations between each of the factors of the MBI for Greek midwives

\begin{tabular}{|c|c|c|c|}
\hline Dimension & $\begin{array}{l}\text { 1.Emotional } \\
\text { exhaustion (EE) }\end{array}$ & $\begin{array}{l}\text { 2.Depersonalization } \\
\text { (DP) }\end{array}$ & $\begin{array}{l}\text { 3.Personal } \\
\text { Accomplishment (PA) }\end{array}$ \\
\hline $\begin{array}{l}\text { Cronbach's a Greek } \\
\text { sample }(N=536)\end{array}$ & 0.85 & 0.74 & 0.73 \\
\hline $\begin{array}{l}\text { Cronbach's a Cypriot } \\
\text { sample }(N=771)\end{array}$ & 0.85 & 0.63 & 0.79 \\
\hline $\begin{array}{l}\text { Cronbach's a US } \\
\text { sample }(N=4163)\end{array}$ & 0.90 & 0.79 & 0.71 \\
\hline 1. EE & - & $0.49^{* *}$ & $-0.30^{* *}$ \\
\hline 2. DP & & - & $-0.34^{* *}$ \\
\hline 3. $P A$ & & & - \\
\hline
\end{tabular}

Reliability analyses revealed a Cronbach's a exceeding 0.7 for all three dimensions, indicating acceptable internal consistency (Nunnally \& Bernstein, 1994). These values are similar to the internal consistency values of the original US results. In particular, the EE scale yields stronger internal consistency values across all three samples.

The Pearson's correlations in Table 2 present significant positive relationships between emotional exhaustion and depersonalization, and significant negative relationships between $\mathrm{PA}$ and $\mathrm{EE}$, and between PA and DP. These results are in line with the psychometric properties of the original MBI (Maslach et al., 1996), and the values yielded by the Cypriot sample. Therefore, the results indicate that the dimensions converge on the same construct.

\section{Differences between Groups}

To examine differences in age and professional experience we conducted 2 oneway ANOVAs. To examine age differences, the sample was classified into 4 age groups; a) 21-30 ( $N=155)$, b) 31-40 ( $N=177)$, c) 41-50 ( $N=153)$, and d) 51-60 ( $N=48)$. Employing the Scheffe post hoc test, statistically significant differences between the first (group a) and the last (group d) age groups across dimensions DP ( $p=0.005$ ) and PA ( $p=0.007$ ) were found. In addition, statistically significant differences were found between group $c$ and group $d$ for the scale of EE $(p<0.05)$, and between group a and group b for the scale of DP ( $p<0.05)$. Overall, it appears that younger participants in this sample reported greater depersonalization, and less personal accomplishment than older participants. The results of the ANOVA are displayed in Tables 3, 4 \& 5 . 
Table 3. Means and standard deviations of the 4 age categories in the three subscales of $\mathrm{MBI}$

\begin{tabular}{llllll}
\hline & & $\mathbf{N}$ & Mean & Std. Deviation & Std. Error \\
\hline \multirow{3}{*}{ Emotional Exhaustion } & AGE & & & & \\
& $21-30$ & 155 & 31,168 & 10,437 & 0,838 \\
& $31-40$ & 177 & 29,751 & 10,370 & 0,779 \\
& $41-50$ & 153 & 32,817 & 12,251 & 0,990 \\
& $51-60$ & 48 & 27,667 & 11,011 & 1,589 \\
& Total & 533 & 30,856 & 11,098 & 0,481 \\
Depersonalization & $21-30$ & 155 & 10,787 & 5,500 & 0,442 \\
& $31-40$ & 177 & 9,096 & 4,819 & 0,362 \\
Personal & $41-50$ & 153 & 9,719 & 5,212 & 0,421 \\
Accomplishment & $51-60$ & 48 & 7,729 & 4,504 & 0,650 \\
& Total & 533 & 9,644 & 5,177 & 0,224 \\
& $21-30$ & 155 & 40,342 & 6,129 & 0,492 \\
& $31-40$ & 177 & 41,955 & 5,996 & 0,451 \\
& $41-50$ & 153 & 41,065 & 6,628 & 0,536 \\
& $51-60$ & 48 & 44,021 & 7,547 & 1,089 \\
& Total & 533 & 41,417 & 6,437 & 0,279 \\
\hline
\end{tabular}

Table 4. ANOVA: Mean differences in Emotional Exhaustion, Depersonalization and Personal Accomplishment between the 4 age categories of the sample $(1=21-30,2=31$ $40,3=41-50,4=51-60$ )

\begin{tabular}{|c|c|c|c|c|c|c|c|}
\hline & & $\begin{array}{l}\text { Sum of } \\
\text { Squares }\end{array}$ & df & $\begin{array}{l}\text { Mean } \\
\text { Square }\end{array}$ & $\mathbf{F}$ & Sig. & $\begin{array}{l}\text { Partial } \\
\text { Eta } \\
\text { Squared }\end{array}$ \\
\hline \multicolumn{8}{|l|}{ Emotional } \\
\hline \multirow[t]{3}{*}{ exhaustion } & Between Groups & 1307.633 & 3 & 435.878 & 3.591 & 0.014 & 0.020 \\
\hline & Within Groups & 64214.243 & 529 & 121.388 & & & \\
\hline & Total & 65521.876 & 532 & & & & \\
\hline \multirow[t]{3}{*}{ Depersonalization } & Between Groups & 432.535 & 3 & 144.178 & 5.516 & 0.001 & 0.030 \\
\hline & Within Groups & 13827.736 & 529 & 26.139 & & & \\
\hline & Total & 14260.270 & 532 & & & & \\
\hline \multicolumn{8}{|l|}{ Personal } \\
\hline \multirow[t]{3}{*}{ accomplishment } & Between Groups & 574.693 & 3 & 191.564 & 4.721 & 0.003 & 0.026 \\
\hline & Within Groups & 21466.841 & 529 & 40.580 & & & \\
\hline & Total & 22041.535 & 532 & & & & \\
\hline
\end{tabular}


Table 5. Post hoc analysis of the mean differences of age categories in the three subscales of MBI using the Scheffe coefficient

\begin{tabular}{|c|c|c|c|c|c|}
\hline Dependent Variable & $\begin{array}{l}\text { (I) } \\
A G E\end{array}$ & $\begin{array}{l}\text { (J) } \\
A G E\end{array}$ & $\begin{array}{l}\text { Mean Difference (I- } \\
\text { J) }\end{array}$ & $\begin{array}{l}\text { Std. } \\
\text { Error }\end{array}$ & Sig. \\
\hline \multirow[t]{12}{*}{ Emotional Exhaustion } & $21-30$ & $31-40$ & 1,416 & 1,212 & 0,714 \\
\hline & & $41-50$ & $-1,649$ & 1,256 & 0,632 \\
\hline & & $51-60$ & 3,501 & 1,820 & 0,297 \\
\hline & $31-40$ & $21-30$ & $-1,416$ & 1,212 & 0,714 \\
\hline & & $41-50$ & $-3,066$ & 1,216 & 0,097 \\
\hline & & $51-60$ & 2,085 & 1,793 & 0,717 \\
\hline & $41-50$ & $21-30$ & 1,649 & 1,256 & 0,632 \\
\hline & & $31-40$ & 3,066 & 1,216 & 0,097 \\
\hline & & $51-60$ & 5,150 & 1,823 & $0,047^{*}$ \\
\hline & $51-60$ & $21-30$ & $-3,501$ & 1,820 & 0,297 \\
\hline & & $31-40$ & $-2,085$ & 1,793 & 0,717 \\
\hline & & $41-50$ & $-5,150$ & 1,823 & $0,047^{*}$ \\
\hline \multirow[t]{12}{*}{ Depersonalization } & $21-30$ & $31-40$ & 1,691 & 0,562 & $0,030^{*}$ \\
\hline & & $41-50$ & 1,068 & 0,583 & 0,340 \\
\hline & & $51-60$ & 3,058 & 0,845 & $0,005^{* *}$ \\
\hline & $31-40$ & $21-30$ & $-1,691$ & 0,562 & 0,030 \\
\hline & & $41-50$ & $-0,623$ & 0,564 & 0,749 \\
\hline & & $51-60$ & 1,367 & 0,832 & 0,441 \\
\hline & $41-50$ & $21-30$ & $-1,068$ & 0,583 & 0,340 \\
\hline & & $31-40$ & 0,623 & 0,564 & 0,749 \\
\hline & & $51-60$ & 1,990 & 0,846 & 0,138 \\
\hline & $51-60$ & $21-30$ & $-3,058$ & 0,845 & $0,005^{* *}$ \\
\hline & & $31-40$ & $-1,367$ & 0,832 & 0,441 \\
\hline & & $41-50$ & $-1,990$ & 0,846 & 0,138 \\
\hline \multicolumn{6}{|l|}{ Personal } \\
\hline \multirow[t]{12}{*}{ Accomplishment } & $21-30$ & $31-40$ & $-1,613$ & 0,701 & 0,153 \\
\hline & & $41-50$ & $-0,723$ & 0,726 & 0,803 \\
\hline & & $51-60$ & $-3,679$ & 1,052 & $0,007^{*}$ \\
\hline & $31-40$ & $21-30$ & 1,613 & 0,701 & 0,153 \\
\hline & & $41-50$ & 0,889 & 0,703 & 0,660 \\
\hline & & $51-60$ & $-2,066$ & 1,037 & 0,266 \\
\hline & $41-50$ & $21-30$ & 0,723 & 0,726 & 0,803 \\
\hline & & $31-40$ & $-0,889$ & 0,703 & 0,660 \\
\hline & & $51-60$ & $-2,955$ & 1,054 & $0,050^{*}$ \\
\hline & $51-60$ & $21-30$ & 3,679 & 1,052 & $0,007^{*}$ \\
\hline & & $31-40$ & 2,066 & 1,037 & 0,266 \\
\hline & & $41-50$ & 2,955 & 1,054 & $0,050^{*}$ \\
\hline
\end{tabular}


Finally, participants were classified into two groups, which were created according to years of professional experience; a) under or equal to 10 years ( $N=245$ ), and b) over 10 years $(N=289)$. Similarly to the US and Cypriot samples, no statistically significant differences in burnout were found between the two groups (Tables 6, 7). Due to the predominance of female participants in our sample (97.6\%), analyses concerning differences in burnout across gender were not conducted.

Table 6. Means and standard deviations of the 2 tenure categories in the three subscales of $\mathrm{MBI}$

\begin{tabular}{llllll}
\hline & Tenure & N & Mean & $\begin{array}{l}\text { Std. } \\
\text { Deviation }\end{array}$ & Std. Error \\
\hline \multirow{2}{*}{ Emotional Exhaustion } & $1-10$ years & 237 & 29,890 & 10,182 & 0,661 \\
& $11+$ years & 287 & 31,704 & 11,737 & 0,693 \\
& Total & 524 & 30,884 & 11,088 & 0,484 \\
Depersonalization & $1-10$ years & 237 & 9,890 & 5,107 & 0,332 \\
& $11+$ years & 287 & 9,404 & 5,207 & 0,307 \\
Personal & Total & 524 & 9,624 & 5,163 & 0,226 \\
Accomplishment & $1-10$ years & 237 & 41,266 & 6,019 & 0,391 \\
& $11+$ years & 287 & 41,575 & 6,715 & 0,396 \\
& Total & 524 & 41,435 & 6,405 & 0,280 \\
\hline
\end{tabular}

Table 7. Mean differences in the 3 subscales of $\mathrm{MBI}$ between the 2 tenure groups of the sample

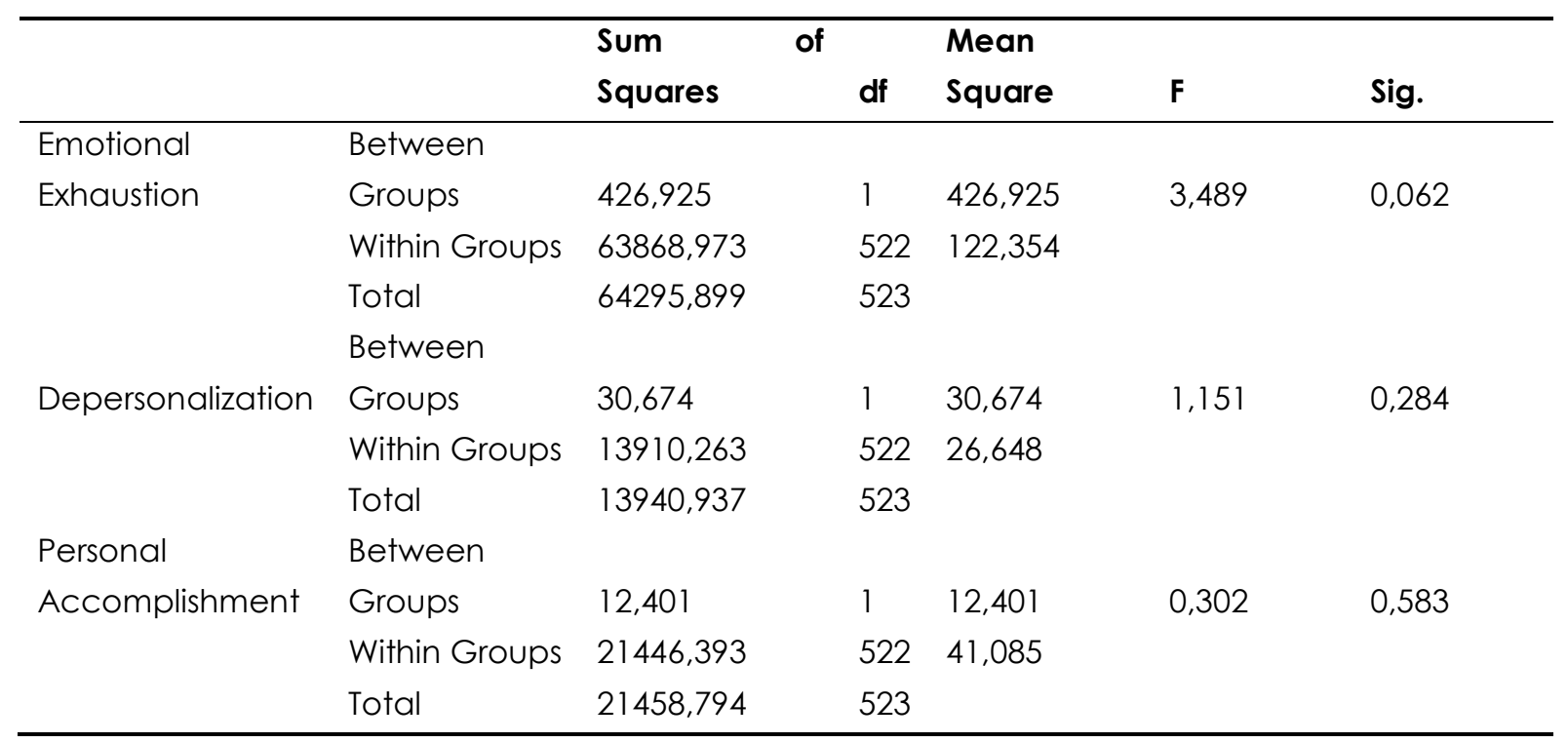


Exploratory Factor Analysis

To examine the factorial structure of the $\mathrm{MBI}$ for the Greek sample of midwives/obstetricians, a Principal Components Analysis (PCA) and varimax rotation was conducted. The results illustrated the presence of 4 main components with an eigenvalue greater than 1.0, explaining 55.95 per cent of the variance. However, a scree plot (figure 1) inspection indicated 3 main components that explain 51.03 per cent of the variance. Both Cypriot and US samples revealed a similar structure. The three components, and factor loadings, are displayed in Table 8.

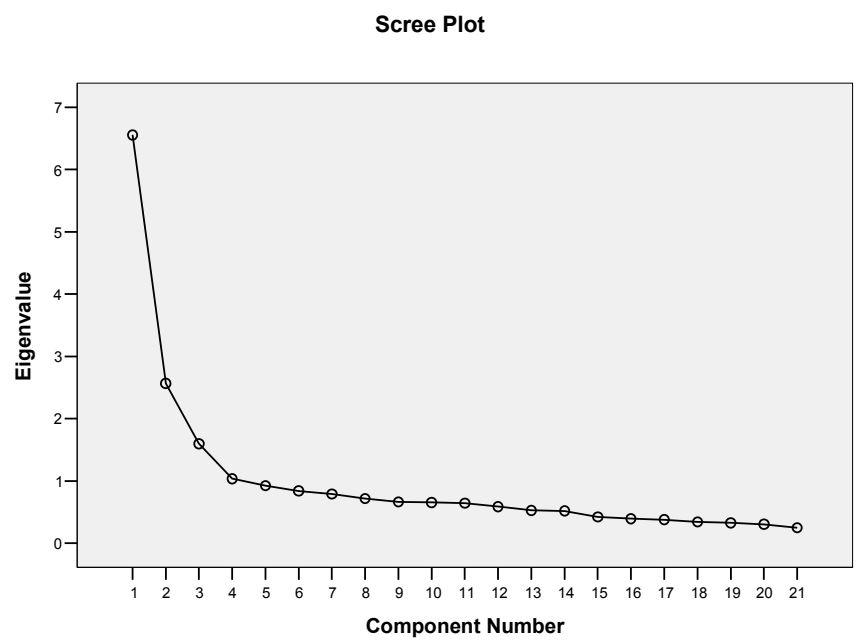

Figure 1. Screeplot of principal components in MBI

Table 8. Factor loadings for the three factor structure with varimax rotation

\begin{tabular}{|c|c|c|c|c|}
\hline \multirow{2}{*}{$\begin{array}{l}\text { Item } \\
\text { numb }\end{array}$} & \multirow[t]{2}{*}{ Factor } & \multicolumn{3}{|c|}{ Factor loadings } \\
\hline & & $\mathrm{EE}$ & DP & PA \\
\hline 2 & $\mathrm{EE}$ & 0.708 & & \\
\hline 20 & EE & 0.700 & & \\
\hline 13 & EE & 0.689 & & \\
\hline 8 & EE & 0.680 & 0.475 & \\
\hline 6 & $\mathrm{EE}$ & 0.661 & & \\
\hline 3 & EE & 0.653 & 0.420 & \\
\hline 16 & EE & 0.507 & & \\
\hline 1 & EE & 0.468 & & \\
\hline 14 & EE & & 0.424 & \\
\hline 11 & DP & 0.602 & & \\
\hline 5 & DP & 0.590 & & \\
\hline 10 & DP & 0.531 & 0.464 & \\
\hline
\end{tabular}




\begin{tabular}{llll}
15 & DP & 0.471 & 0.451 \\
21 & PA & 0.492 & \\
9 & PA & -0.411 & 0.559 \\
19 & PA & -0.440 & 0.443 \\
17 & PA & -0.463 & 0.488 \\
12 & PA & -0.623 & \\
18 & PA & -0.638 & \\
7 & PA & & 0.529 \\
4 & PA & & 0.492 \\
\hline
\end{tabular}

Note: Only factor loadings $>0.40$ are shown

The factor loadings presented in Table 8 above show a considerable divergence from the results of the Cyprus sample, where almost all items load onto the first component (EE) of the burnout structure proposed by Maslach et al., (1996). With the exception of items 4, 7 , and 14, which load onto the second component (DP dimension), the remaining items $(3,8,9,10,17$ and 19) equally load onto both the first and second components. Finally, the third component of the $\mathrm{MBI}$ consists of only one factor loading: that of item 15.

The results of the factor analysis of burnout as it is experienced in Greece indicate a single or dual factor composition, predominantly associated with emotional exhaustion. The assertion that burnout consists of 2 factors, whereby emotional exhaustion encompasses the component of depersonalization is supported by the research of Densten (2001).

\section{Discussion}

The present study attempted to examine the psychometric properties and the factor structure of the Maslach Burnout Inventory (MBI) amongst Greek health professionals, against the data of two other samples (Kokkinos, 2006; Maslach et al., 1996). According to the results, this scale exhibited satisfactory reliability coefficients for all three dimensions of Maslach's burnout framework, in congruence with the results of the US and Cypriot teacher samples. Specifically, the dimension of emotional exhaustion (EE) yielded the strongest internal consistency as predicted by the original test manual, and in replication of other similar studies, despite that the current sample consisted of midwives as opposed to teaching professionals assessed previously (Kokkinos, 2006; Maslach et al., 1996; Schaufeli \& Janczur, 1994). The results substantiate past evidence that the Greek translation of the $\mathrm{MBI}$ is a reliable tool in assessing burnout across Greek samples. 
In consideration of validity, intercorrelations between the three dimensions indicated statistically significant relationships in the expected directions. Emotional exhaustion and depersonalization are positively and strongly related to each other, although negatively related to personal accomplishment. Once again, these results replicate those of past studies conducted in other countries (Schaufeli \& Janczur, 1994), and which also single out emotional exhaustion as a key characteristic of burnout.

The results of our factor analysis demonstrated support for Densten's (2001) twodimensional structure of burnout, despite Maslach's assertion that EE and PA continue to be separate substructures of the construct. Several previous studies have yielded similar effects, in that burnout is made up of two components, or even a single key component (Lee \& Ashforth, 1996, Leiter, 1993). For instance, Leiter and Maslach (1988) claimed that burnout is characterised primarily by emotional exhaustion, in which feelings of depersonalization and reduced personal accomplishment arise as a consequence of EE. Likewise, the results of the present study revealed that EE is a core symptom of burnout, closely intertwined with the dimensions of DP and PA as indicated by the strong convergent validity between subscales. However, differences between age groups reveal a lack of support for the developmental onset of burnout, since younger participants exhibited greater degrees of psychological distance with others (DP), and greater feelings of personal inadequacy in relation to their contribution at work (PA), in contrast to their older peers.

On average, the experience of emotional exhaustion and personal accomplishment within the Greek sample was more intense compared to the analogous Cypriot and US samples. In fact, a comparison of the mean scores of both the EE and PA subscales across all three samples suggests that as emotional exhaustion increases, so do feelings of achievement and accomplishment. Of course, the presumption that EE predicts PA requires empirical confirmation. In any case, differences in the results between the three samples may be attributed to differences between the corresponding workplace environments, as well as characteristics of each profession. The incorporation of a broader range of occupations in future Greek studies may assist in providing more generalizable results for the Greek population. In addition, future studies may wish to examine the influences of additional variables on the experience of burnout, such as one's freedom in selecting their workplace environment, and possibly the differences that urban vs rural employment location has in the manifestation of burnout. 
It appears, in conclusion, that the Greek translation of the MBI is a tool that can be applied with confidence as a reliable and valid measure of burnout amongst Greek professionals. However, the fact that in this context it reveals a two-dimensional structure, as opposed to three-dimensional, raises questions surrounding its diagnostic capabilities, and warrants further examination of its factorial structure across a greater variety of professions, and larger sample of participants. In addition, confirmatory factor analysis (CFA) and an assessment of the validity of the experiential model of burnout could provide important insight into additional facets of this construct. In any case, the $\mathrm{MBI}$ continues to offer diagnostic, and possibly preventative, insight into the emotional, interpersonal, and regulatory aspects of one's professional well-being, in hope that burnout may be avoided.

\section{References}

Adali, E. \& Lemonidou C. (2001). Factors of burnout in nursing staff. Nursing, 2, 15-22.

Ahola, K., \& Hakanen, J. (2007). Job strain, burnout, and depressive symptoms: A prospective study among dentists. Journal of Affective Disorders, 104, 103-110.

Anagnostopoulos, F., \& Papadatou, D. (1992). Factorial structure and internal consistency of the MBI in nurses. Psychological Issues, 5, 3, 183-202.

Bakker, R. H., Groenewegen, P. P., Jabaaij, L, Meijer, W., Sixma, H. \& de Veer, A. (1996). 'Burnout' among Dutch midwives. Midwifery. 12(4):174-81.

Bakker, A. B., Schaufeli, W. B., Demerouti, E., Janssen, P. M. P., Van der Hulst, R., \& Brouwer, J. (2000). Using equity theory to examine the difference between burnout and depression. Anxiety, Stress, \& Coping, 13, 247-268.

Bakker, A. B., Schaufeli, W. B., Sixma, H. J., Bosveld, W., \& VanDierendonck, D. (2000). Patient demands, lack of reciprocity, and burnout: A five-year longitudinal study among general practitioners. Journal of Organizational Behavior, 21 , 425441.

Borritz, M., Bültmann, U., Rugulies, R., Christensen, K. B., Villadsen, E., \& Kristensen, T. S. (2005). Psychosocial work characteristics as predictors for burnout: Findings from 3-year follow up of the PUMA study. Journal of Occupational and Environmental Medicine, 47, 1015-1025. 
Chatzimihaloglou, A., Moraitou, M., \& Emmanouil, E. (2005). Stress and depression measurement in nursing staff. Paper session in the $3^{\text {rd }}$ Scientific Conference "Research and new data in midwifery". Athens, Parisianou Publications.

Chatzimihaloglou, A., Moraitou, M., \& Stalikas, A. (2003). Stress and depression measurement in midwifes. Paper session in the $1^{\text {st }}$ Scientific Conference "Research and new data in midwifery". Athens, Parisianou Publications.

Demerouti, E., Bakker, A. B., Nachreiner, F., \& Schafueli, W. B. (2001). The job demandsresources model of burnout. Journal of Applied Psychology, 86, 499-512.

Densten, L. I. (2001). Re-Thinking Burnout. Journal of Organizational Behavior, Vol. 22, No. 8 (Dec., 2001), pp. 833-847.

Engelbrecht, S. (2006) Motivation and burnout in human service work. The case of midwifery in Denmark. AMl. www.nyt-om-arbejdsliv.dk

Freudenburger, H. J. (1974). Staff burnout. Journal of Social Issues, 30, 159-165.

Galanakis, M., Stalikas A., Kallia, H., Karagianni, C., \& Karela, C., (2009). Gender differences in experiencing occupational stress: the role of age, education and marital status. Stress and Health, in print.

González-Romá, V., Schaufeli, W. B., Bakker, A. B., \& Lloret, S. (2002). Burnout and work engagement: Independent factors or opposite poles? Journal of Vocational Behavior, 68, 165-174.

lacovides, A., Fountoulakis, K. N., Moysidou, C. \& lerodiakonou, C. (1999). Burnout in nursing staff: is there a relationship between depression and burnout? Journal of Psychiatry Med. 29 (4), 421-33.

lerodiakonou, C., \& lakovides, A. (1997). Occupational fatigue in the nursing staff of general hospitals. Psychiatric matters in General Hospital, Thessalonica, Mastoridis Publications.

Iwanacki, E.F., \& Scwabb, R.L., (1981). A cross validation study of the Maslach Burnout Inventory. Educational and Psychological Measurement, 41, 1167-1174.

Kiuru, N., Aunola, K., Nurmi, J.-E., Leskinen, E., \& Salmela-Aro, K. (2008). Peer group influence and selection in adolescents' school burnout: A longitudinal study. Merrill-Palmer Quarterly, 54, 23-55. 
Kokkinos, C. M. (2000). Burnout in Greek primary school teachers: Cross cultural data on the Maslach Burnout Inventory. Paper presented at XXXVIlth International Congress, of Psychology, Stockholm, Sweden.

Kokkinos, C. M. (2006). Factor structure and psychometric properties of the Maslach Burnout Inventory-Educators Survey among elementary and secondary school teachers in Cyprus. Stress and Health, Vol 22, No 1, pg: 25-33.

Laschinger, H. K. S., \& Leiter, M. P. (2006). The impact of nursing work environments on patient safety outcomes: The mediating role of burnout/engagement. Journal of Nursing Administration, 5, 259-267.

Lee, R. T. \& Ashforth, B. E. (1996). A Further Examination of Managerial Burnout: Toward an Integrated Model. Journal of Organizational Behavior, 14, 3-20.

Leiter, M. P. (2005). Perception of risk: An organizational model of burnout, stress symptoms, and occupational risk. Anxiety, Stress, \& Coping, 18, 131-144.

Leiter, M. P. (1993). Burnout as a Developmental Process: Consideration of Models. In W. B. Schaufeli, C. Maslach \& T. Marek (eds), Professional Burnout: Recent Developments in Theory and Research (pp. 237-249). London: Taylor \& Francis.

Leiter, M. P., Day, A., Harvie, P., \& Shaughnessy, K. (2007). Personal and organizational knowledge transfer: Implications for work life engagement. Human Relations, 60, 259-283.

Leiter, M. P., \& Maslach, C. (2005). A mediation model of job burnout. In A. S. G. Antoniou \& C. L. Cooper (Eds.), Research companion to organizational health psychology (pp. 544-564). Cheltenham, United Kingdom: Edward Elgar.

Leiter, M. P. \& Maslach, C. (1988) The Impact of Interpersonal Environment on Burnout and Organizational Commitment. Journal of Organizational Behavior, Vol. 9, No. 4, pp. 297-308.

Maslach C. (1978). Job Burnout - How people cope. Public Welfare. Volume:36, Issue:2, pp. 56-58.

Maslach, C. (1993). Burnout: a Multidimensional Perspective. In W. B. Schaufeli, C. Maslach \& T. Marek (eds.), Professional Burnout: Recent developments in Theory and Research (pp. 19-32). London: Taylor \& Francis. 
Maslach, C. \& Jackson, S. E. (1981). The Measurement of Experience Burnout. Journal of Occupational Behavior, 2, 99-113.

Maslach, C. \& Jackson, S. E. (1982). Burnout in Health Professions: A Social Psychological Analysis. In G. Sansers \& J. Suls (eds.), Social Psychology and Health Illness (pp. 227-251). Hillsdale, NJ: Erlbaum.

Maslach, C. \& Jackson, S. E. (1986). Maslach Burnout Inventory: Manual (2nd). Palo Alto, CA: Consulting Psychologists Press.

Maslach, C., Jackson, S. E. \& Leiter, M. P. (1996). Maslach Burnout Inventory: Manual(3nd). Palo Alto, CA: Consulting Psychologists Press.

Maslach, C., \& Leiter, M. P. (2005). Stress and burnout: The critical research. In C. L. Cooper (Ed.), Handbook of stress medicine and health (2nd ed., pp. 153-170). London: CRC Press.

Maslach, C. \& Pines A. (1977). The Burn-Out Syndrome in the Day Care Setting. Child Care Quarterly, 7, 100-113.

Melissa, C., Avramika, M., \& Laloumi, B., (2003). Burnout in nurses. Hellenic Psychiatry 1, 1, 30-34.

Montgomery, A. J., Panagopolou, E., \& Benos, A. (2006). Work-family interference as a mediator between job demands and job burnout among doctors. Stress and Health, 22, 203-212.

Mpellali, A. (1998). Psychological burden in nursing staff - Occupational fatigue. Post graduate seminars in nursing oncology and psycho-oncology. Greek Nursing Studies Association, Athens, Greece.

Nunally, J.C., \& Burnstein, I.H. (1994). Psychometric theory. New York: McGraw-Hill.

Ouzouni, C. (1999). Psychological distress of nursing staff in the intensive care department. Post graduate seminars in nursing oncology and psychooncology. Greek Nursing Studies Association, Athens, Greece.

Papadatou, D., \& Anagnostopoulos F., (1999). Burnout. Post graduate seminars in nursing oncology and psycho-oncology. Greek Nursing Studies Association, Athens, Greece. 
Papathanasiou, M. (2007). Burnout in health care professionals and its relationship with demographic variables and psychological health. Psychology, 14, 1, 14-25.

Pines, A. M., \& Keinan, G. (2005). Stress and burnout: The significant difference. Personality and individual differences, 39, 625-635.

Pines, A. \& Maslach, C. (1978). Characteristics of Staff Burnout in Mental Health Settings. Hospital \& Community Psychiatry, 29, 233-237.

Rupert, P. A., \& Kent, J. S. (2007). Gender and work setting differences in career sustaining behaviours and burnout among professional psychologists. Professional Psychology: Research and Practice, 38, 88-96.

Rupert, P. A., \& Morgan, D. J. (2005). Work setting and burnout among professional psychologists. Professional Psychology: Research and Practice, 36, 544-550.

Sandall, J. (1998). Occupational burnout in midwives: new ways of working and the relationship between organizational factors and psychological health and wellbeing Risk Decision and Policy, 3, 3, 213-232.

Schaufeli, W. B., \& Bakker, A. B. (2004). Job demands, job resources, and their relationship with burnout and engagement: A multi-sample study. Journal of Organizational Behavior, 25, 293-315.

Schaufeli B. W. \& Janczur B. (1994) Burnout among nurses. Journal of Cross-Cultural Psychology, Vol. 25, No. 1, 95-113.

Schaufeli, W.B., Martinez, I., Pinto, A.M., Salanova, M., \& Bakker, A. (2002). Burnout and engagement in university students: A cross-national study. Journal of CrossCultural Psychology, 33, 464-481.

Shirom, A. (2002). Job related burnout: A review. In J. C. Quick \& L. E. Tetrick (Eds.), Handbook of occupational health psychology (pp. 245-264). Washington, DC: American Psychological Association.

Truchot, D., \& Deregard, M. (2001). Perceived inequity, communal orientation and burnout: The role of helping models. Work \& Stress, 15, 347-356.

Vahey, D. C., Aiken, L. H., Sloane, D. M., Clarke, S. P., \& Vargas, D. (2004). Nurse burnout and patient satisfaction. Medical Care, 42, 57-66. 
Ziogou, T., Mpimpou, I., Dimetriou, E., Kiouzepas, I., \& lakovides, A. (1998). Occupational distress in phychiatric nursing staff. Nursing, 1, 62-70. 